\section{(A) OPEN ACCESS}

\title{
Short-term outcome of endoscopic versus microscopic pituitary adenoma surgery: a systematic review and meta-analysis
}

\author{
Mario Ammirati, ${ }^{1}$ Lai Wei, ${ }^{2}$ Ivan Ciric ${ }^{3}$
}

'Department of Neurosurgery, Ohio State University, Columbus, Ohio, USA ${ }^{2}$ Center for Biostatistics, Ohio State University, Columbus, Ohio, USA

${ }^{3}$ Department of Neurosurgery, North Shore University Health System, Evanston, IL, USA

\section{Correspondence to}

Professor Mario Ammirati, Department of Neurosurgery, Ohio State University, 410 West 10th Avenue, N1025 Doan Hall, Columbus, OH 43210, USA;

mario.ammirati@osumc.edu

Received 17 May 2012

Revised 18 September 2012

Accepted 13 November 2012

Published Online First

15 December 2012

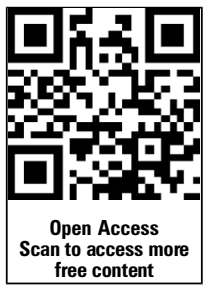

\section{S Linked}

- http://dx.doi.org/10.1136/ jnnp-2012-304541

- http://dx.doi.org/10.1136/ jnnp-2012-304583

- http://dx.doi.org/10.1136/ jnnp-2013-305130

To cite: Ammirati $\mathrm{M}$, Wei $\mathrm{L}$, Ciric I. J Neurol Neurosurg Psychiatry 2013;84: 843-849.

\section{ABSTRACT}

Endoscopic transsphenoidal pituitary surgery has become increasingly more popular for the removal of pituitary adenomas. It is also widely recognised that transsphenoidal microscopic removal of pituitary adenomas is a well-established procedure with good outcomes. Our objective was to meta-analyse the shortterm results of endoscopic and microscopic pituitary adenoma surgery. We undertook a systematic review of the English literature on results of transsphenoidal surgery, both microscopic and endoscopic from 1990 to 2011. Series with less than 10 patients were excluded. Pooled data were analysed using meta-analysis techniques to obtain estimate of death, complication rates and extent of tumour removal. Complications evaluated included cerebrospinal fluid leak, meningitis, vascular complications, visual complications, diabetes insipidus, hypopituitarism and cranial nerve injury. Data were also analysed for tumour size and sex. 38 studies met the inclusion criteria yielding 24 endoscopic and 22 microscopic datasets (eight studies included both endoscopic and microscopic series). Meta-analysis of the available literature showed that the endoscopic transsphenoidal technique was associated with a higher incidence of vascular complications $(p<0.0001)$. No difference was found between the two techniques in all other variables examined. Meta-analysis of the available literature reveals that endoscopic removal of pituitary adenoma, in the short term, does not seem to confer any advantages over the microscopic technique and the incidence of reported vascular complications was higher with endoscopic than with microscopic removal of pituitary adenomas. While we recognise the limitations of meta-analysis, our study suggests that a multicentre, randomised, comparative effectiveness study of the microscopic and endoscopic transsphenoidal techniques may be a reasonable approach towards establishing a true valuation of these techniques.

\section{INTRODUCTION}

The most widely used approach to remove pituitary adenomas since the 1960s has been the transsphenoidal route, executed using the operating microscope. This approach is generally regarded as being associated with good outcomes. ${ }^{1}$ However, starting approximately 15 years ago and more so in the past 5 years, there has been a trend towards using endoscopic transsphenoidal techniques for the removal of pituitary adenomas. ${ }^{2-5}$ Endoscopic techniques have been recommended reportedly because of their lesser invasiveness, fewer complications and overall better results compared to microscopic microsurgical techniques. ${ }^{5}$ In the absence of significant randomised clinical trials on the subject, a systematic review of published results of microsurgical and endoscopic techniques in the treatment of pituitary adenomas may be appropriate in comparing the two techniques.

\section{METHODS}

\section{Search strategy}

The MEDLINE (1990 to present) and the EMBASE (1990 to present) databases were the information source used. The following keywords were searched individually or in association: pituitary, adenoma, sella, transsphenoidal, endoscopy, microscopic, Cushing's disease, prolactinoma, acromegaly, endonasal, minimally invasive surgery, complication, skull base and surgery. The included limits were: English for the language category and humans for the study category. The date of the last search was August 2011.

\section{Study selection criteria}

Series with 10 or more patients with pituitary adenoma, operated on using either microscopic or endoscopic techniques were included. Manuscripts in which the approach was guided by the endoscope and tumour removal was carried out using the microscope were included in the microscope group. As the intent of this report was to analyse the results of papers in which transsphenoidal surgery (either endoscopic or microscopic) was deemed to be the best modality to treat pituitary adenoma, we excluded reports in which a decision had been made preoperatively to use a combined transsphenoidal and intracranial approach. ${ }^{6}$ Series including mixed pathology and in which it was not possible to extrapolate the adenoma results were also excluded. ${ }^{7-11}$

\section{Mined data}

Mined data include year of publication, study design, number and sex of subjects, size of the adenoma (micro vs macro), death, cerebrospinal fluid leak, meningitis, vascular complications, visual complications, diabetes insipidus transient and permanent, hypopituitarism, cranial nerve injury and complete versus partial resection. Vascular complications included carotid or other vessels injury, intracerebral haematoma, or any symptomatic intratumoral or intrasellar haemorrhage. Venous bleeding from the cavernous sinus was tabulated as a vascular complication when it prevented the completion of the surgical 
procedure. Epistaxis was not included among the vascular complications. Cerebrospinal fluid leak included all postoperative leaks and all patients who developed an intra-operative leak requiring lumbar drainage. Decreased postoperative anterior pituitary function did not include Cushing's patients receiving postoperative cortisol or patients in whom a hypophysectomy was carried out.

\section{Statistical analysis}

There were 38 studies that fulfilled the inclusion criteria. ${ }^{1} 3$ 12-47 All of them except one that was prospective and randomised ${ }^{27}$ were retrospective studies. Only eight out of these 38 studies reported data on complications from both the endoscopic and microscopic surgery groups. ${ }^{15} 17 \quad 18212732 \quad 3645$ Only one of these eight studies was prospective and randomised, with only 10 patients in each arm, ${ }^{27}$ the others being retrospective studies. In six out of these seven studies the endoscopic and microscopic patients were accrued along longitudinally different time frames. ${ }^{171821323645}$ Furthermore, in two of these seven studies tumour resection was either not evaluated at all, ${ }^{15}$ or was judged by the surgeon at the time of the operation. ${ }^{45}$ In addition, not all of these studies reported data on other relevant metrics (ie, tumour size, vascular and or visual complications). Due to the overall limitations of these studies we felt that we could have got more useful information by analysing all the data reported in the literature that fulfilled our inclusion criteria. Given the nature of the studies available in the literature it was not possible to compare the results (eg, complication rates) of endoscopic surgery to microscopic surgery using the traditional meta-analysis method with relative risk or OR. Instead, weighted summary rates and 95\% CI of death and major complications/events (cerebrospinal fluid leak, meningitis, vascular complications, visual loss, diabetes insipidus temporary or permanent, hypopituitarism, complete resection, and nerve injury) were provided using the appropriate meta-analysis models (ie, random effects or fixed effects) for endoscopic and microscopic surgery, respectively. Then we compared the outcomes between endoscopic and microscopic surgery using the estimated proportions and SE (ie, 95\% CI). Freeman-Tukey double arcsine transformation is used for proportions. ${ }^{48}$ Tests for heterogeneity were performed for each meta-analysis. Based on results of the heterogeneity, test, random-effects (heterogeneity present) or fixed-effects (heterogemeity absent) models were chosen to estimate the results. ${ }^{49}$ Using this methodology, each study was weighted more fairly than giving more weight to those studies with larger sample sizes, especially when the interstudy variation was larger than the intrastudy variation. Tabaee et $a l^{5}$ used this methodological approach in 2009 when reviewing endoscopic pituitary surgery. The meta-analysis was performed using 'meta' package from the $\mathrm{R}$ statistical software. ${ }^{50}$

\section{RESULTS}

Sixteen manuscripts dealt with transsphenoidal endoscopic

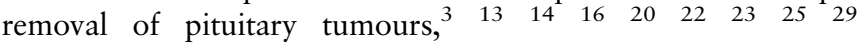

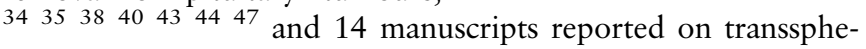
noidal removal of pituitary tumours using the operating micro-

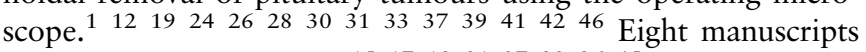

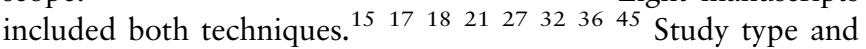
demographics of all the studies are presented in table 1.

Estimated proportions with 95\% CI of macro tumour size and women were obtained using meta-analysis techniques.

We failed to detect any statistically significant difference in the two groups regarding the proportion of macro tumour size (endoscopic: $79.75 \%$ with $95 \%$ CI of $73.20 \%$ to $85.58 \%$; microscopic: $66.90 \%$ with $95 \%$ CI of $47.54 \%$ to $83.67 \%$ ) and women (endoscopic: $54.49 \%$ with $95 \%$ CI of $51.44 \%$ to $57.52 \%$; microscopic: $54.51 \%$ with $95 \%$ CI of $47.58 \%$ to $61.35 \%$ ).

We also used meta-analysis techniques to estimate the death and complications rates. Based on the test of heterogeneity results, random-effects pooled or fixed-effects pooled rates were estimated for death, cerebrospinal fluid leak, meningitis, vascular complications, visual complication, diabetes insipidus temporary, diabetes insipidus permanent, hypopituitarism, complete resection and nerve injury with endoscopic and microscopic surgery, respectively (table 2). Fixed-effects pooled estimates of the death rate with endoscopic and microscopic surgery were computed because there was no evidence of heterogeneity $(\mathrm{p}=0.84$ and 1$)$. The pooled death rates were $0.49 \%(95 \% \mathrm{CI}$ $0.23 \%$ to $0.84 \%$ ) and $0.23 \%$ (95\% CI $0.10 \%$ to $0.42 \%$ ) for endoscopic and microscopic surgery, respectively. The fixed-effects pooled meningitis rate $(p=0.86$, test for heterogeneity) for endoscopic surgery and the random-effects pooled meningitis rate $(\mathrm{p}<0.0001$, test for heterogeneity) for microscopic surgery were $1.11 \%$ (95\% CI $0.64 \%$ to $1.71 \%$ ) and $2.08 \%$ (95\% CI $0.83 \%$ to $3.86 \%$ ). The fixed-effects pooled estimates of vascular complications were calculated for endoscopic and microscopic surgery $(\mathrm{p}=0.87$ and 0.39 , test for heterogeneity), which were $1.58 \%$ (95\% CI $1.07 \%$ to $2.19 \%$, figure 1 ) and $0.50 \% \quad(95 \%$ CI $0.28 \%$ to $0.78 \%$, figure 2$)$. The fixed-effects or random-effects pooled estimates of visual complication rate $(\mathrm{p}=0.50$ and 0.04 , heterogeneity) and nerve injury rate $(p=0.48$ and 0.01 , heterogeneity) were calculated for endoscopic and microscopic surgery, respectively, and are listed in table 2.

The random-effects pooled estimates with 95\% CI of cerebrospinal fluid leak rate (both $\mathrm{p}<0.0001$, test for heterogeneity), temporary diabetes insipidus rate (both $\mathrm{p}<0.0001$, heterogeneity), permanent diabetes insipidus rate $(p=0.02$ and $<0.0001$, heterogeneity) and hypopituitarism rate (both $\mathrm{p}<0.0001$, heterogeneity) for endoscopic and microscopic surgery were also calculated and listed in table 2 . We failed to demonstrate any statistically significant difference in the pooled rate of death, cerebrospinal fluid leak, meningitis, visual complication, diabetes insipidus temporary, diabetes insipidus permanent, hypopituitarism, complete resection and nerve injury between endoscopic and microscopic surgery using the estimated proportions and SE. On the other hand, the vascular complication rate in endoscopic surgery is higher than in microscopic surgery (figures 1 and $2, p<0.0001$ ) from those studies reporting the vascular complication information. Furthermore, the macro tumours or the extent of complete tumour resection, two variables that could have affected the vascular complication rate, were found not to be statistically significant in the endoscopic or microscopic series reporting vascular complications $(\mathrm{p}=0.24$ and 0.10 for macro tumour size and complete resection, respectively).

\section{DISCUSSION}

\section{Transsphenoidal microscopic pituitary surgery}

Transsphenoidal microscopic pituitary surgery is a time confirmed effective way of treating pituitary adenomas, as shown by the low incidence of complications in any clinical/practice setting according to the Ciric-sponsored survey of the late $1990 \mathrm{~s},{ }^{1}$ although a statistically significant difference was noted in terms of better results in the hands of more experienced surgeons. Microscopic pituitary surgery relies on three-dimensional visualisation and thus on the ability to operate in threedimensional space. Important conceptual nuances that need to be implemented in its execution to lead to optimal results are the recognition that the pituitary gland is a midline, extra- 
Table 1 Study types and demographics

\begin{tabular}{|c|c|c|c|c|c|c|c|}
\hline Authors & Year & Duration of study & Operation type & No of patients & Mean age, years (range) & Women (\%) & Macroadenomas (\%) \\
\hline Jho and Carrau ${ }^{3}$ & 1997 & $1993-6$ & Endoscopic & 44 & 38 (14-88) & $19(43)$ & $31(70)$ \\
\hline Cappabianca et $a l^{14}$ & 2002 & 1997-2001 & Endoscopic & 146 & $46.1(16-74)$ & $76(52)$ & $125(86)$ \\
\hline White et $a l^{45}$ & 2004 & $2000-2$ & Endoscopic & 50 & 41.1 (NA) & $26(52)$ & NA \\
\hline Senior et al ${ }^{40}$ & 2008 & NA & Endoscopic & 148 & 46 (NA) & $81(55)$ & $114(81) \dagger$ \\
\hline Netea-Meier et $a \beta^{35}$ & 2006 & 1998-2004 & Endoscopic & 35 & $41(14-68)$ & $25(71)$ & $6(17)$ \\
\hline Rudnik et $a \beta^{38}$ & 2005 & $2001-2$ & Endoscopic & 63 & $48.3(11-77)$ & $34(54)$ & $52(83)$ \\
\hline Kenan et al ${ }^{29}$ & 2006 & $1997-2005$ & Endoscopic & 78 & $44.7(11-67)$ & NA & $67(86)$ \\
\hline Jain et $a^{27}$ & 2007 & NA & Endoscopic & 10 & 40.1 (NA) & $6(60)$ & $9(90)$ \\
\hline Uren et $a l^{43}$ & 2007 & $2001-5$ & Endoscopic & 32 & $53(25-69)$ & $12(38)$ & $23(72)$ \\
\hline Frank et $a l^{22}$ & 2006 & 1998-2004 & Endoscopic & 381 & $48(7-89)$ & $227(60)$ & $284(75)$ \\
\hline Dehdashti et $a l^{20}$ & 2008 & $2004-7$ & Endoscopic & 200 & $49.9(20-78)$ & $109(55)$ & $158(79)$ \\
\hline Charalampaki et al ${ }^{16}$ & 2007 & $2004-5$ & Endoscopic & 50 & 56 (28-84) & $30(60)$ & $41(82)$ \\
\hline Yano et a $\left.\right|^{44}$ & 2009 & $2001-8$ & Endoscopic & 194 & $53(15-85)^{*}$ & $120(62)$ & NA \\
\hline Zhang et $a l^{47}$ & 2008 & $1998-2005$ & Endoscopic & 78 & $45.1(15-76)$ & $42(54)$ & $67(86)$ \\
\hline Campbell et $a l^{13}$ & 2010 & $2005-9$ & Endoscopic & 26 & $45.7(20-69)$ & $12(46)$ & 22 \\
\hline Gondim et $a^{23}$ & 2010 & 1998-2009 & Endoscopic & 301 & $42(12-79)$ & $167(55)$ & 248 \\
\hline Hofstetter et $a^{25}$ & 2010 & 2004-10 & Endoscopic & 24 & $50.7(22-75)$ & $11(46)$ & 19 \\
\hline Nakao et al ${ }^{34}$ & 2011 & $2000-8$ & Endoscopic & 43 & $55(31-75)$ & $20(46)$ & 43 \\
\hline Casler et al ${ }^{15}$ & 2005 & $1996-2003$ & Endoscopic & 15 & 41.6 & $9(60)$ & NA \\
\hline Duz et $a l^{21}$ & 2008 & 1996-2007 & Endoscopic & 28 & NA & NA & NA \\
\hline Choe et al ${ }^{17}$ & 2008 & $2004-7$ & Endoscopic & 12 & $47 \pm 12$ & 7 (58) & 9 \\
\hline $0^{\prime}$ Malley et $\left.a\right|^{36}$ & 2008 & $2003-8$ & Endoscopic & 25 & $47.9(18-73)$ & $10(40)$ & 22 \\
\hline$D^{\prime}$ Haens et al ${ }^{18}$ & 2009 & $2001-7$ & Endoscopic & 60 & $37(10-70)$ & $41(68)$ & 31 \\
\hline Messerer et $a l^{32}$ & 2011 & $2006-9$ & Endoscopic & 82 & $57(20-82)$ & $35(43)$ & 82 \\
\hline Jain et $a l^{27}$ & 2007 & NA & Microscopic & 10 & $31.6(18-58)$ & $5(50)$ & $8(80)$ \\
\hline Mortini et $a^{\beta 3}$ & 2005 & 1990-2002 & Microscopic & 1140 & $43(8-82)$ & $681(60)$ & $788(69)$ \\
\hline Höybye et $\left.a\right|^{26}$ & 2004 & $1990-9$ & Microscopic & 34 & $40(13-74)$ & $26(76)$ & $2(6)$ \\
\hline White et $a{ }^{45}$ & 2004 & $1996-9$ & Microscopic & 50 & 43.5 (NA) & $17(34)$ & NA \\
\hline Ciric et al ${ }^{1}$ & 1997 & NA & Microscopic & 638 & NA & NA & NA \\
\hline De et $a l^{19}$ & 2003 & 1980-2001 & Microscopic & 90 & $61(29-86)$ & $46(51)$ & $61(68)$ \\
\hline Rees et $\left.a\right|^{37}$ & 2002 & $1980-2000$ & Microscopic & 54 & $41.3(14-73)$ & $42(78)$ & $10(19)$ \\
\hline Shimon et $\left.a\right|^{42}$ & 2002 & $1990-2000$ & Microscopic & 74 & $39(8-72)$ & $64(86)$ & $3(4)$ \\
\hline Han et $a l^{24}$ & 2008 & 1996-2006 & Microscopic & 592 & 42.3 (NA) & $274(46)$ & $592(100) \ddagger$ \\
\hline Kaltsas et $a l^{28}$ & 2001 & $1993-8$ & Microscopic & 67 & $46(12-80)^{*}$ & $31(46)$ & $50(75)$ \\
\hline Kreutzer et $a^{31}$ & 2001 & $1992-8$ & Microscopic & 57 & $43.9(16-71)$ & $37(65)$ & $38(67)$ \\
\hline Semple and Laws ${ }^{39}$ & 1999 & $1992-7$ & Microscopic & 105 & $38.5(6-78)$ & $83(79)$ & $13(12)$ \\
\hline Zhang et $a l^{46}$ & 1999 & $1982-97$ & Microscopic & 208 & $47.5(16-71)$ & $110(53)$ & $208(100)$ \\
\hline Koren et al ${ }^{30}$ & 1999 & $1993-5$ & Microscopic & 37 & NA & NA & $23(62)$ \\
\hline Badie et $a l^{12}$ & 2000 & $1996-9$ & Microscopic & 34 & 45.5 (NA) & $17(50)$ & $21(62)$ \\
\hline Sheehan et $a l^{41}$ & 1999 & $1995-7$ & Microscopic & 70 & $58.5(25-85)$ & $21(30)$ & $70(100)$ \\
\hline Casler et $a l^{15}$ & 2005 & 1996-2003 & Microscopic & 15 & 50.6 & $10(67)$ & NA \\
\hline Choe et $a l^{17}$ & 2008 & 1997-2004 & Microscopic & 11 & $48 \pm 10$ & $9(82)$ & 8 \\
\hline O'Malley et $a l^{36}$ & 2008 & $2003-8$ & Microscopic & 25 & $50.8(23-78)$ & $10(40)$ & 23 \\
\hline Duz et $a l^{21}$ & 2008 & $1996-2007$ & Microscopic & 65 & NA & NA & NA \\
\hline$D^{\prime}$ Haens et $a l^{18}$ & 2009 & $2001-7$ & Microscopic & 60 & $35(10-68)$ & $16(27)$ & 27 \\
\hline Messerer et $\left.a\right|^{32}$ & 2011 & 2005 & Microscopic & 82 & $56.5(27-84)$ & $35(43)$ & 82 \\
\hline
\end{tabular}

*Median age.

†Adenoma size was only available in 140 of 148 patients.

fIncluding 438 macro and 154 giant.

arachnoidal structure, and that the normal anterior pituitary gland is distended by the macroadenoma into a thin layer of tissue surrounding the pathology, whose preservation maximises postoperative pituitary function. ${ }^{51}$ Therefore, microscopic pituitary surgery needs to be extra-arachnoidal, to respect the principle of midline and needs to try to identify and preserve normal pituitary tissue.
Endoscopic pituitary surgery

Endoscopic pituitary surgery has been advocated for the surgical treatment of pituitary adenomas since the late 1990s on the basis of its panoramic improved visualisation and thus the ability to visualise structures easily such as the optico-carotid recesses and to access suprasellar areas visually that are not in the direct line of vision during microscopic pituitary 
Table 2 Estimated proportion with $95 \% \mathrm{Cl}$ of complications/events for endoscopy and microscopy

\begin{tabular}{|c|c|c|c|c|}
\hline Complication/events & $\begin{array}{l}\text { No of studies for } \\
\text { endoscopy }\end{array}$ & $\begin{array}{l}\text { Proportion }(95 \% \mathrm{Cl}) \text { for } \\
\text { endoscopy }\end{array}$ & $\begin{array}{l}\text { No of studies for } \\
\text { microscopy }\end{array}$ & $\begin{array}{l}\text { Proportion }(95 \% \mathrm{Cl}) \text { for } \\
\text { microscopy }\end{array}$ \\
\hline Death & 19 & $0.49 \%(0.23 \%$ to $0.84 \%) \dagger$ & 18 & $0.23 \%(0.10 \%$ to $0.42 \%) \dagger$ \\
\hline Cerebrospinal fluid leak & 24 & $7.00 \%(4.84 \%$ to $9.52 \%)$ & 19 & $6.34 \%(3.86 \%$ to $9.37 \%)$ \\
\hline Meningitis & 13 & $1.11 \%(0.64 \%$ to $1.71 \%) \dagger$ & 14 & $2.08 \%(0.83 \%$ to $3.86 \%)$ \\
\hline Vascular complications* & 17 & $1.58 \%(1.07 \%$ to $2.19 \%) \dagger$ & 12 & $0.50 \%(0.28 \%$ to $0.78 \%) \dagger$ \\
\hline Visual loss & 13 & $0.72 \%(0.37 \%$ to $1.19 \%) \dagger$ & 14 & $0.60 \%(0.23 \%$ to $1.14 \%)$ \\
\hline Diabetes insipidus temporary & 18 & $9.10 \%(6.57 \%$ to $11.99 \%)$ & 14 & $10.23 \%(6.50 \%$ to $14.69 \%)$ \\
\hline Diabetes insipidus permanent & 21 & $2.31 \%(1.41 \%$ to $3.41 \%)$ & 15 & $4.25 \%(1.96 \%$ to $7.36 \%)$ \\
\hline Hypopituitarism & 17 & $8.51 \%(5.16 \%$ to $12.59 \%)$ & 12 & $11.64 \%(5.14 \%$ to $20.32 \%)$ \\
\hline Complete resection & 22 & $68.77 \%(64.37 \%$ to $73.00 \%)$ & 18 & $64.44 \%(57.62 \%$ to $70.98 \%)$ \\
\hline Nerve injury & 8 & $0.28 \%(0.05 \%$ to $0.71 \%) \dagger$ & 7 & $0.53 \%(0.08 \%$ to $1.34 \%)$ \\
\hline
\end{tabular}

surgery. 52022 This improved visualisation was felt to be theoretically associated with a greater extent of resection and improved safety, less invasiveness and potential better results-compared to microscopic pituitary surgery. ${ }^{5}$ However, endoscopic pituitary surgery is bidimensional and thus depth perception is missing, although manoeuvres have been recommended to minimise this drawback. $^{21}$ The three surgical principles as described under microscopic surgery should also be applicable to endoscopic surgery.

\section{Results of our study}

Our study did not demonstrate any short-term advantages of endoscopic pituitary adenoma surgery. The review of the literature suggests an increased incidence of vascular complications associated with it. Recognising the limitations of a systematic review in coming to firm conclusions, it is conceivable that the greater incidence of vascular complications associated with the endoscopic transsphenoidal surgical technique is the consequence of either a more robust sphenoid exposure of the carotid optic recess with a greater potential for carotid artery injury, or the lack of three-dimensional depth perception during suprasellar manoeuvres. Indeed, the majority of vascular complications associated with the endoscopic technique involved suprasellar vascular injuries including intracerebral haemorrhages, midbrain stroke, mesencephalic haemorrhage, posterior cerebral artery laceration and internal carotid artery injury. $^{14} 162240$

\section{Other possible advantages of endoscopic pituitary surgery}

Other theoretical advantages of endoscopic pituitary surgery such as its limited invasiveness or minimally invasive feature, leading to an overall better quality of life, have not been addressed by our study. ${ }^{162938} 4047$ Indeed, the only study that looked at outcome and quality of life after endoscopic surgery for pituitary adenomas showed only 'a trend to improved scores in the endoscopic group compared with previous studies in patients treated by conventional approaches'. ${ }^{52}$ A recent study has reported a $29.6 \%$ incidence of extracranial complications following endoscopic transsphenoidal sellar surgery, with the majority of them being prolonged nasal crusting $(10.8 \%)$ and synechiae formation $(8.8 \%) .{ }^{53}$ Again, without making a definitive statement, it appears plausible that these nasal complications are the consequence of liberal and repetitive passage of instrumentation through the nasal cavity. That is even more likely to occur whenever nasal septal flaps are developed. Postoperative nasal debridement is usually required. ${ }^{8}$
Figure 1 Proportion of vascular complications with endoscopy. Test for heterogeneity: $Q=10.01$ on 16 degrees of freedom $(p=0.87)$.

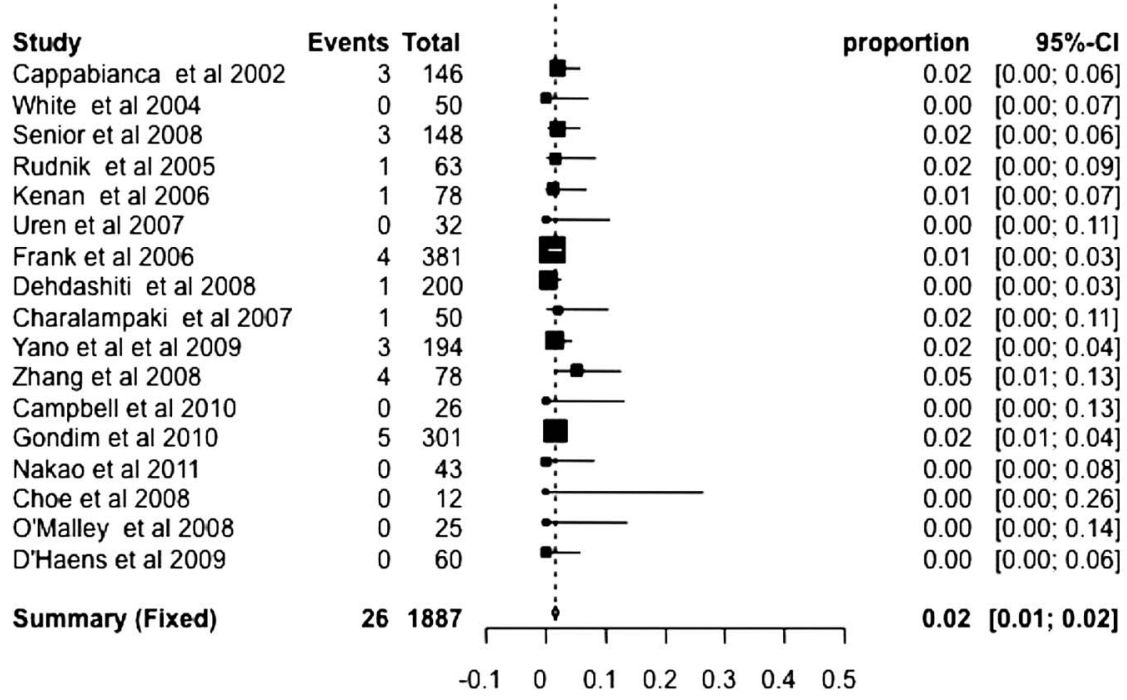

Proportions of vascular complications with endoscopy Test for heterogeneity: $Q=10.01$ on 16 degrees of freedom $(p=0.87)$ 
Figure 2 Proportion of vascular complications with microscopy. Test for heterogeneity: $Q=11.67$ on 11 degrees of freedom $(p=0.39)$.

\section{Study \\ Mortini et al 2005 \\ Hoybye et al 2004 \\ White et al 2004 \\ Ciric et al 1997 \\ DE et al 2003 \\ Han et al 2008 \\ Semple and Laws 1999 \\ Zhang et al 1999 \\ Sheehan et al 1999 \\ Choe et al 2008 \\ O'Malley et al 2008 \\ D'Haens et al 2009}

Summary (Fixed)

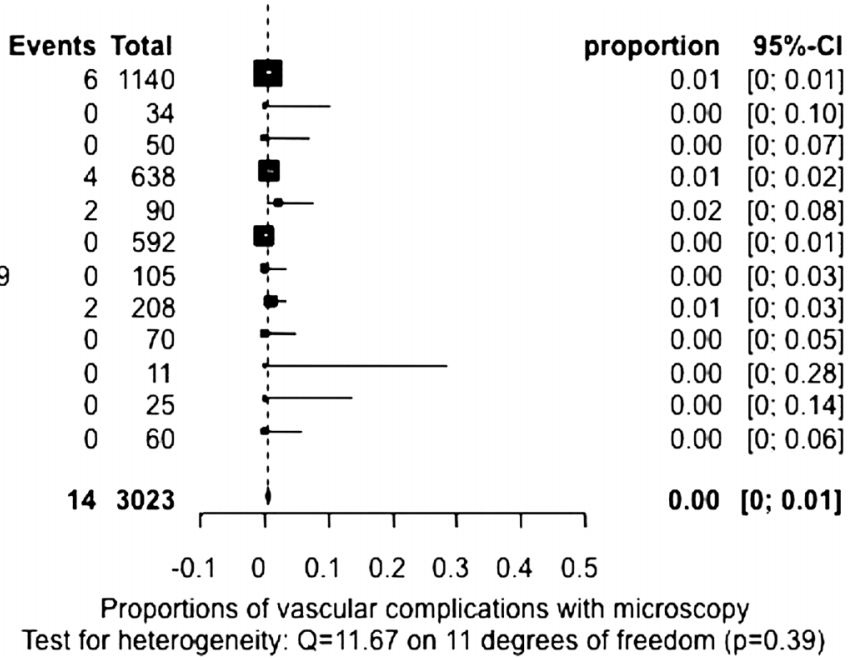

possible, ${ }^{58}$ The colloquium proposed a progressive algorithm, 'the IDEAL recommendations', to evaluate surgical innovations. ${ }^{58}$ Stage 1 , the idea phase, should be prompted by the need for a new solution to a clinical problem. It is essentially the proof of a concept and is implemented in only a few patients with careful outcome-especially negative outcome-reporting.

Stage 2a, the development phase, involves the planned use of the procedure in a small group of selected patients to accrue outcome on the safety of the procedure and its technical and procedural success or lack thereof. Protocols should be registered beyond the surgeons' institution to secure equipoise and should undergo some form of ethical approval and informed research consent. It is our belief that endoscopic transsphenoidal surgery has fulfilled splendidly the requirements under these two progressive algorithm stages.

Stage $2 \mathrm{~b}$, the exploration phase, involves the evaluation of the outcome of a rather well-defined procedure in a larger group of patients. Rigorous prospective trials looking at short-term outcomes (technical clinical and patient centered) need to be employed in this stage. Clearly, stringent quality controls need to be in place.

Stage 3, the assessment phase, involves well-defined indications, a stable procedure executed by many surgeons and the comparison of this procedure with the gold standard procedure. This is usually done using randomised clinical trials or alternative well-structured trials, such as parallel group nonrandomised studies, controlled interrupted-time series studies, tracker trials or similar designs. Again, institutional review board approval and informed research consent are mandatory.

Stage 4, the long-term study phase, is a surveillance study wherein the now established procedure is evaluated for rare and long-term outcomes. No ethical approval is necessary.

\section{Endoscopic pituitary surgery and the IDEAL framework}

It appears that 12 years after the publication of one of the first peer-reviewed papers on the use of endoscopic pituitary surgery $^{26}$ the advantages of the procedure are still not fully consolidated in accordance with the above algorithm for the evaluation of new surgical techniques. Clearly, the introduction of new surgical technology/procedures, such as endoscopic transsphenoidal surgery, is both a laudatory step towards innovation as well as a complex process requiring rigorous scrutiny with evidence-based methods such as discussed above or a similar acceptable variant thereof. ${ }^{58-60}$ 


\section{CONCLUSIONS}

Meta-analysis of available literature on endoscopic transsphenoidal removal of pituitary adenomas seems to suggest that the endoscopic technique is associated with a higher incidence of vascular complications compared to microscopic transsphenoidal removal of pituitary adenomas. Moreover, in the short term, the same analysis of the literature reveals that there is no clear, unequivocal advantage to endoscopic transsphenoidal removal compared to microscopic transsphenoidal removal of pituitary adenomas.

Contributors MA, LW and IC all contributed to the conception and design of the article, to the data acquisition, analysis and interpretation. They were all involved in critically drafting/revising the article for important intellectual content. Finally, they all gave final approval of the version to be published.

\section{Funding None.}

\section{Competing interests None.}

Provenance and peer review Not commissioned; externally peer reviewed.

Open Access This is an Open Access article distributed in accordance with the Creative Commons Attribution Non Commercial (CC BY-NC 3.0) license, which permits others to distribute, remix, adapt, build upon this work non-commercially, and license their derivative works on different terms, provided the original work is properly cited and the use is non-commercial. See: http://creativecommons.org/ licenses/by-nc/3.0/

\section{REFERENCES}

1 Ciric I, Ragin A, Baumgartner C, et al. Complications of transsphenoidal surgery: results of a national survey, review of the literature, and personal experience. Neurosurgery 1997;40:225-37.

2 Cavallo LM, Dal Fabbro M, Jalalod'din H, et al. Endoscopic endonasal transsphenoidal surgery. Before scrubbing in: tips and tricks. Surg Neurol 2007;67:342-7.

3 Jho HD, Carrau RL. Endoscopic endonasal transsphenoidal surgery: experience with 50 patients. J Neurosurg 1997;87:44-51.

4 Powell M, Gnanalinghan KK. Endoscopic trans-sphenoidal pituitary surgery: is it here to stay? Br J Neurosurg 2007;21:315-17.

5 Tabaee A, Anand VK, Barron Y, et al. Endoscopic pituitary surgery: a systematic review and meta-analysis. J Neurosurg 2009;111:545-54.

6 Kabil MS, Eby JB, Shahinian HK. Fully endoscopic endonasal vs. transseptal transsphenoidal pituitary surgery. Minim Invasive Neurosurg 2005;48:348-53.

7 Graham SM, Iseli TA, Karnell LH, et al. Endoscopic approach for pituitary surgery improves rhinologic outcome. Ann Otol Rhinol Laryngol 2009;118:630-5.

8 Higgins TS, Courtemanche C, Karakla D, et al. Analysis of transnasal endoscopic versus transseptal microscopic approach for excision of pituitary tumors. Am J Rhinol 2008;22:649-52.

9 Jho HD. Endoscopic transsphenoidal surgery. J Neurooncol 2001;54:187-95.

10 Neal JG, Patel SJ, Kulbersh JS, et al. Comparison of techniques for transsphenoidal pituitary surgery. Am J Rhinol 2007;21:203-6.

11 Shah S, Har-El G. Diabetes insipidus after pituitary surgery: incidence after traditional versus endoscopic transsphenoidal approaches. Am J Rhinol 2001;15:377-9.

12 Badie B, Nguyen P, Preston JK. Endoscopic-guided direct endonasal approach for pituitary surgery. Surg Neurol 2000;53:168-73.

13 Campbell PG, Kenning E, Andrews DW, et al. Outcome after a purely endoscopic transsphenoidal resection of growth hormone-secreting pituitary adenomas. Neurosurg Focus 2010;29:E5

14 Cappabianca P, Cavallo LM, Colao A, et al. Surgical complications associated with the endoscopic endonasal transsphenoidal approach for pituitary adenomas. J Neurosurg 2002;97:293-8.

15 Casler JD, Doolittle AM, Mair EA. Endoscopic surgery of the anterior skull base. Laryngoscope 2005;115:16-24

16 Charalampaki P, Reisch R, Ayad A, et al. Endoscopic endonasal pituitary surgery: surgical and outcome analysis of 50 cases. J Clin Neurosci 2007;14:410-15.

17 Choe JH, Lee KS, Jeun SS, et al. Endocrine outcome of endoscopic endonasal transsphenoidal surgery in functioning pituitary adenomas. J Korean Neurosurg Soc 2008:44:151-5.

18 D’Haens J, Van Rompaey K, Stadnik T, et al. Fully endoscopic transsphenoidal surgery for functioning pituitary adenomas. A retrospective comparison with traditional transsphenoidal microsurgery in the same institution. Surg Neurol 2009;72:336-40

19 De $\mathrm{P}$, Rees DA, Davies $\mathrm{N}$, et al. Transsphenoidal surgery for acromegaly in Wales: results based on stringent criteria of remission. J Clin Endocrinol Metab 2003:88:3567-72.
20 Dehdashti AR, Ganna A, Karabatsou K, et al. Pure endoscopic endonasal approach for pituitary adenomas: early surgical results in 200 patients and comparison with previous microsurgical series. Neurosurgery 2008;62:1006-17.

21 Duz B, Harman F, Secer HI, et al. Transsphenoidal approaches to the pituitary: a progression in experience in a single center. Acta Neurochir 2008;150: 1133-39.

22 Frank $G$, Pasquini $E$, Farneti $G$, et al. The endoscopic versus the traditional approach in pituitary surgery. Neuroendocrinology 2006;83:240-8.

23 Gondim JA, Almeida JPC, Albuquerque LAF, et al. Endoscopic endonasal approach for pituitary adenoma: surgical complications in 301 patients. Pituitary 2011 14:174-83

24 Han ZL, He DS, Mao ZG, et al. Cerebrospinal fluid rhinorrhea following trans-sphenoidal pituitary macroadenoma surgery: experience from 592 patients. Clin Neurol Neurosurg 2008;110:570-9.

25 Hofstetter CP, Mannaa RH, Mubita L, et al. Endoscopic endonasal transsphenoidal surgery for growth hormone-secreting pituitary adenomas. Neurosurg Focus 2010;29:E6.

26 Hoybe $C$, Grenback E, Thoren M, et al. Transsphenoidal surgery in Cushing disease: 10 years of experience in 34 consecutive cases. J Neurosurg 2004;100:634-8.

27 Jain AK, Gupta AK, Pathak A, et al. Excision of pituitary adenomas: randomized comparison of surgical modalities. Br J Neurosurg 2007;21:328-31.

28 Kaltsas GA, Isidori AM, Florakis $D$, et al. Predictors of the outcome of surgical treatment in acromegaly and the value of the mean growth hormone day curve in assessing postoperative disease activity. J Clin Endocrinol Metab 2001;86:1645-52.

29 Kenan K, Ihsan A, Dilek 0, et al. The learning curve in endoscopic pituitary surgery and our experience. Neurosurg Rev 2006;29:298-305.

30 Koren I, Hadar T, Rappaport ZH, et al. Endoscopic transnasal transsphenoidal microsurgery versus the sublabial approach for the treatment of pituitary tumors: endonasal complications. Laryngoscope 1999;109:1838-40.

31 Kreutzer J, Vance ML, Lopes MB, et al. Surgical management of GH-secreting pituitary adenomas: an outcome study using modern remission criteria. J Clin Endocrinol Metab 2001;86:4072-77.

32 Messerer M, De Battista JC, Raverot G, et al. Evidence of improved surgical outcome following endoscopy for nonfunctioning pituitary adenoma removal. Personal experience and review of the literature. Neurosurg Focus 2011;30:E11.

33 Mortini $P$, Losa M, Barzaghi $R$, et al. Results of transsphenoidal surgery in a large series of patients with pituitary adenoma. Neurosurgery 2005;56:1222-33.

34 Nakao N, Itakura T. Surgical outcome of the endoscopic endonasal approach for non-functioning giant pituitary adenoma. J Clin Neurosci 2011;18:71-5.

35 Netea-Meier RT, van Lindert EJ, den Heijer M, et al. Transsphenoidal pituitary surgery via the endoscopic technique: results in 35 consecutive patients with Cushing's disease. Eur J Endocrinol 2006;154:675-84

36 O'Malley B, Grady SM, Gabel BJ, et al. Comparison of endoscopic and microscopic removal of pituitary adenomas: single-surgeon experience and the learniong curve. Neurosurg Focus 2008;25:E10.

37 Rees DA, Hanna FW, Davies JS, et al. Long-term follow-up results of transsphenoidal surgery for Cushing's disease in a single centre using strict criteria for remission. Clin Endocrinol (Oxf) 2002:56:541-51.

38 Rudnik A, Zawadzki TR, Wojtacha M, et al. Endoscopic transnasal transsphenoidal treatment of pathology of the sellar region. Minim Invasive Neurosurg 2005;48:101-7.

39 Semple PL, Laws ER Jr. Complications in a contemporary series of patients who underwent transsphenoidal surgery for Cushing's disease. J Neurosurg 1999;91:175-9

40 Senior BA, Ebert CS, Bednarski KK, et al. Minimally invasive pituitary surgery. Laryngoscope 2008;118:1842-55.

41 Sheehan MT, Atkinson JL, Kasperbauer JL, et al. Preliminary comparison of the endoscopic transnasal vs the sublabial transseptal approach for clinically nonfunctioning pituitary macroadenomas. Mayo Clin Proc 1999;74:661-70.

42 Shimon I, Ram Z, Cohen ZR, et al. Transsphenoidal surgery for Cushing's disease: endocrinological follow-up monitoring of 82 patients. Neurosurgery 2002;51:57-62.

43 Uren B, Vrodos N, Wormald PJ. Fully endoscopic transsphenoidal resection of pituitary tumors: technique and results. Am J Rhinol 2007;21:510-14.

44 Yano S, Kawano T, Kudo M, et al. Endoscopic endonasal transsphenoidal approach through the bilateral nostrils for pituitary adenomas. Neurol Med Chir 2009;49:1-7.

45 White DR, Sonnenburg RE, Ewend MG, et al. Safety of minimally invasive pituitary surgery (MIPS) compared with a traditional approach. Laryngoscope 2004;114:1945-48.

46 Zhang $X$, Fei Z, Zhang J, et al. Management of nonfunctioning pituitary adenomas with suprasellar extensions by transsphenoidal microsurgery. Surg Neurol 1999:52:380-5.

47 Zhang $X$, Fei Z, Zhang W, et al. Endoscopic endonasal transsphenoidal surgery for invasive pituitary adenoma. J Clin Neurosci 2008;15:241-5.

48 Miller JJ. The inverse of the Freeman-Tukey double arcsine transformation. Am Statistician 1978:32:138.

49 Whitehead A. Meta-Analysis of controlled clinical trials. Chichester, UK: John Wiley \& Sons Ltd, 2002:151-74. 
50 Schwarzer G. Meta-analysis with R (reference manual of package 'meta' in R). The $R$ foundation for statistical computing (Publisher), Vienna, Austria:2010:1-65.

51 Ciric I, Rosenblatt S, Baumgarter C, et al. Transsphenoidal microsurgery. Neurosurgery 2002;51:161-9.

52 Karabatsou K, O'Kelly C, Ganna A, et al. Outcomes and quality of life assessment in patients undergoing endoscopic surgery for pituitary adenomas. $\mathrm{Br} J$ Neurosurg 2008;22:630-5.

53 Kilty SJ, McLaughlin N, Bojanowski MW, et al. Extracranial complications of endoscopic transsphenoidal sellar surgery. I Otolaryngol Head and Neck Surg 2010:39:309-14.

54 Goudakos JK, Markou KD, Georgalas C. Endoscopic versus microscopic trans-sphenoidal pituitary surgey: a systematic review and meta-analysis. Clin Otolaryngol 2011;36:212-20.
55 Rotenberg B, Tam S, Ryu WHA, et al. Microscopic versus endoscopic pituitary surgery: a systematic review. Laryngoscope 2010;120:1292-97.

56 Strychowsky J, Nayan S, Reddy K, et al. Purely endoscopic transsphenoidal surgery versus traditional microsurgery for resection of pituitary adenomas: systematic review. J Otolaryngol Head Neck Surg 2011:40:175-85.

57 Dusick JR, Esposito F, Mattozo CA, et al. Endonasal transsphenoidal surgery: the patient's perspective - survey results from 259 patients. Surg Neurol 2006;65:332-42.

58 McCulloch P, Altman DG, Campbell WB, et al. No surgical innovation without evaluation: the IDEAL recommendations. Lancet 2009;374:1105-12.

59 Ashrafian H, Rao C, Darzi A, et al. Benchmarking in surgical research. Lancet 2009;374:1045-7.

60 Horton R. Surgical research or comic opera: questions, but few answers. Lancet 1996;347:984-5 